\title{
DA PÓS-GRADUAÇÃO AS ESCRITAS SOBRE ORIENTAÇÕES DE DISSERTAÇÕES E TESES: UMA ENTREVISTA COM LUCÍDIO BIANCHETTI
}

Como parte das comemorações dos 10 anos do PPGEdu da Unisc, trazemos uma entrevista com o professor Lucídio Bianchetti, da Universidade Federal de Santa Catarina, SC. Autor e pesquisador experiente, Lucídio tem desenvolvido importantes pesquisas em campos do conhecimento da pós-graduação, tendo contribuído para a pesquisa e os debates no país sobre orientação e escrita de teses e dissertações, atividade que, desde o início de sua caminhada, constitui objeto de seus estudos. A principal obra do autor nesse campo de pesquisa é a A Bússola do Escrever: desafios e estratégias na orientação de teses e dissertações (Cortez, 2010). Organizada juntamente com Maria Neto Machado, reúne textos de autores sobre a temática.

Nascido em David Canabarro, ex-distrito de Passo Fundo, no Rio Grande do Sul, Lucídio trilhou sua caminhada por várias universidades, tendo atuado na Universidade de Passo Fundo, RS e Universidade Estadual de Maringá, PR, até se firmar na Universidade Federal de Santa Catarina, onde, desde 1992, vem desenvolvendo sua carreira profissional. Entre outras atividades, foi coordenador do Programa de Pós-Graduação em Educação da UFSC. No PPGE/UFSC, atua na linha de pesquisa Trabalho, Educação e Política.

Em seu estágio pós-doutoral, sob orientação de José Alberto Correia, na Universidade do Porto, Lucídio desbravou os meandros do Tratado de Bolonha, reforma universitária realizada nas instituições de ensino europeias que unificou o sistema de ensino superior, e cujos reflexos podemos ver também nas universidades brasileiras. A pesquisa gerou a obra $O$ processo de Bolonha e a globalização da educação superior, lançada pela Mercado das Letras (2015), com versão em espanhol pela CLACSO (2016). O mesmo processo, junto à Mercado de Letras e a CLACSO, ocorreu com o recente livro Da universidade à commoditycidade, juntamente com Valdemar Sguissardi (2017).

Ainda no âmbito do ensino superior, publicou o livro educação corporativa. Mundo do trabalho e do conhecimento: aproximações (2005), organizado com Elisa Maria Quartiero, uma coletânea de textos que versa sobre a penetração e organização cada vez maior das instituições empresariais no ensino superior. Outra de suas obras, juntamente com lone R. Valle e Gilson R. de M. Pereira, traz como título: O fim dos intelectuais acadêmicos? Induções da Capes e desafios às associações científicas, publicado pela Autores Associados (2015). E também o livro Publique, apareça ou pereça: produtivismo acadêmico, 'pesquisa administrada' e plágio nos tempos da cultura digital (2018), sua mais recente obra, juntamente com Antônio Álvaro Zuin e Obdália Ferraz. A obra foca a crescente exigência de publicações no sistema da pós-graduação braileira e outras decorrências, destacadas no subtítulo. Além destas, destaca-se também a coletânea coorganizada com Ari Paulo Jantsch: Interdisciplinaridade. Para além da filosofia do sujeito, obra que está em sua ga edição (2011), publicada pela Vozes. 
Pesquisador produtividade no $\mathrm{CNPq}(\mathrm{Pq} 1 \mathrm{~B})$ e autor de vários outros livros, Lucídio é sujeito ativo e militante no interior da pós-graduação brasileira, tendo integrado a direção da Associação Nacional de Pós-Graduação como vice-presidente pela região Sul na gestão 2003-2005, participado de comissões de avaliação da Comissão de Aperfeiçoamento de Nível Superior (CAPES) e Conselho Nacional de Pesquisa (CNPq), entre outros.

Mas a motivação principal dessa entrevista, realizada por Moacir Fernando Viegas, um dos editores de Reflexão e Ação, é o fato do pesquisador ter acompanhado de perto a trajetória do PPGEdu Unisc, desde os primeiros passos, no início dos anos 2000, por meio de assessorias e conversas informais, juntamente com outros professores, como Maria Isabel Cunha. Nesse sentido, a entrevista é também uma homenagem ao papel importante desempenhado por Lucídio na ainda jovem caminhada dos professores e professoras do programa de pós-graduação em Educação da Universidade de Santa Cruz do Sul.

MFV: Bom, Lucídio, em primeiro lugar, muito obrigado por aceitar conceder essa entrevista para nós. Neste momento em que o Programa de Pós-Graduação em Educação da Unisc (PPGEdu/UNISC) está comemorando 10 anos, ela possui um valor especial. E tu participaste, pudeste acompanhar de perto esta caminhada, seja por meio de assessorias ou de diálogos informais, sempre estando à disposição para emitir tuas impressões e esclarecer dúvidas pontuais que surgiram durante o processo. Então iniciamos essa conversa te agradecendo pelo aceite.

LB: O agradecimento é meu. Este convite muito me honra e desafia. Espero poder contribuir.

MFV: Lucídio, tu já tens uma longa trajetória acadêmica, que muitos de nós acompanhamos, mesmo antes de iniciarmos o Programa. Assim, considero importante que descrevas brevemente essa trajetória, falando sobre a área de conhecimento em que atuas e sobre as pesquisas que estás desenvolvendo atualmente.

LB: Então, Moacir, para começar, graduei-me em Pedagogia. No período em que eu concluí o curso, em 1978, não era comum um estudante recém graduado ir direto para a pós-graduação. Mas, na época, sobrou uma bolsa do Plano Institucional de Capacitação Docente (PICD/CAPES) e como eu havia atuado no diretório acadêmico e tinha um percurso de inserções nas discussões na universidade, o diretor me chamou e perguntou se eu gostaria de fazer mestrado. Imagine se eu não ia desafiar-me a ingressar na Pós-graduação (PG)? Então, de 1979 a 1982, fiz o mestrado em educação na PUC (Pontifícia Universidade Católica) do Rio de Janeiro e depois passei a trabalhar na UPF (Universidade de Passo Fundo/RS), onde permaneci até 1988. Na época, embora as universidades se caracterizem pela organização em ensino, pesquisa e extensão, eu acabei fazendo ensino e extensão. Para as atividades de pesquisa praticamente não sobrava tempo e nem havia desafios, estímulos e necessidades como agora. Em seguida, trabalhei quatro anos na Universidade Estadual de Maringá (UEM), que foi minha primeira inserção numa universidade pública, no caso, estadual, mas ainda num momento em que estava me afirmando profissionalmente. Após esse período, fiz concurso na UFSC (Universidade Federal de Santa Catarina), assumindo em 1992. Começa aí, então, em minha trajetória, a possibilidade de trabalhar com pesquisa e extensão, além de ensino. $\mathrm{Na}$ UFSC isso me foi 
proporcionado. Em seguida, depois de um intervalo de 18 anos, inicio o doutorado. Faço doutorado em Educação na PUC de São Paulo, orientado pelo Celso Ferreti, trabalhando questões relacionadas à educação e trabalho e novas tecnologias, temáticas com as quais eu continuo mantendo atualmente um vínculo, embora, a partir de um ponto que eu irei fazer menção em seguida, eu tenha passado a ter como âncora a pós-graduação, a orientação de dissertações e teses, a questão da coordenação, da CAPES e o próprio Processo de Bolonha, no decorrer do estágio pós-doutoral na Universidade do Porto (PT). Retomando a questão da formação, ao concluir o doutorado retorno para a UFSC, onde está criada uma situação no PPGE que em nada se assemelha às situações de hoje. Ao retornar com o doutorado concluído, eu nem preciso procurar o Programa para inserir-me na pós-graduação. A própria coordenação me diz: "o que você está fazendo que ainda não foi se credenciar no mestrado para dar aula, para orientar, para assumir a pós-graduação?" Eu me surpreendi com a conclamação a ingressar na PG. Até fiquei muito envaidecido, pois esperava que essa vinculação à PG demoraria mais, mas era um tempo em que havia muito pouca gente titulada e muitas pessoas se aposentaram em função do Plano Collor. Então, mediante esse fato, eu volto do doutorado e já começo a dar aulas e orientar. E, por incrível que pareça, em questão de menos um ano eu já era vice coordenador do Programa de PG, e em seguida, concluído o período como vice, assumo a coordenação do PPGE.

MFV: E como foi assumir a gestão do Programa?

LB: Foi o maior baque, o maior impacto na minha vida, porque eu assumo um Programa que havia perdido a nota 5 , passando para 4 . Se a gente não fizesse um trabalho de alinhamento às exigências da CAPES, nós corríamos o risco de perder o doutorado na avaliação seguinte. Então eu quero te dizer que meu processo de entrada na PG foi um choque, um choque de realidade, e me defrontei com algo que eu chamaria de uma espécie de "processo civilizatório", induzido e imposto pela CAPES, no sentido de levar todos a desenvolver-se e pautar-se em um modelo único de PG. O que eu quero registrar, ainda sobre este período, é que foi uma experiência de aprendizagem muito importante, principalmente pela convivência com os colegas do Fórum de Coordenadores de Programas de PG (Forpred), que à época denominava-se Eduforum. Eram muitos desafios. Eram muitas frentes de trabalho. $\mathrm{Na}$ época, nós peitávamos o mestrado profissional de frente. Fizemos uma resistência até 2009, com o argumento de que o mestrado profissional na área da Educação era o acadêmico e a argumentação prevaleceu. Só que em 2009 foram injetados recursos e abriram-se os mestrados profissionais, e estamos aí com mais de 40 cursos. E confesso que tendo analisado algumas propostas desses cursos eu venho mudando minha posição e compreensão sobre o mestrado profissional, percebendo aspectos extremamente positivos, em termos, por exemplo, de gestão e de diversos aspectos relacionados à educação básica. Têm muitas coisas boas sendo feitas, e logo logo, como o doutorado foi aprovado, teremos doutorados profissionais e, é provável que, com o tempo venhamos a ter bons doutorados profissionais também. Então, fechando essa parte, eu diria que essa experiência na gestão da pós-graduação, que deu origem a um texto que está num livro publicado em coorganização com o Valdemar Sguissardi (Dilemas da Pós-Graduação. Gestão e Avaliação, publicado pela Autores Associados), cujo título é "Os dilemas do coordenador de Programa de PG: entre o acadêmico-pedagógico e o burocrático-administrativo", que a gente faz uma plataforma, promete, jura 
que vai priorizar o acadêmico-pedagógico e, entrando no trabalho, acaba sendo consumido por uma espécie de voragem burocrático-administrativa, quando então as boas intenções da gente ficam nas boas intenções porque a parte burocrática nos toma.

MFV: Vou aproveitar que tu trouxeste os temas principais da tua trajetória de pesquisa, os mais recentes principalmente, e te perguntar sobre um deles, que é justamente a orientação de teses e dissertações, questão que inclusive te trouxe ao PPGEdu da Unisc para um Seminário. Quais as dificuldades que hoje tu vês que professores e alunos enfrentam nessa atividade de orientação? Gostaria também que tu falasses um pouco sobre tua experiência como orientador, destacando pontos que consideras essenciais.

LB: A tua pergunta me dá o ensejo de resgatar um fato que eu considero muito decisivo para ter entrado nessa vertente de pesquisa sobre pós-graduação, orientação e gestão. Em 1999, Ana Maria Netto Machado e eu mandamos um texto para a reunião da SBPC com o tema "orientação de dissertações e teses" e recebemos um parecer que, em certos aspectos, foi até ofensivo. Isto porque era dito que este não era um tema de pesquisa, isto é, que orientação não era um tema de pesquisa, rejeitando, assim, nosso trabalho. Aquilo nos chocou muito, porque a gente não estava acostumado a receber nãos ao submeter artigos ou trabalhos para eventos. Ressalto, porém, e isso fomos aprendendo, que receber nãos é muito importante. Também é um exercício receber nãos quando a gente manda um trabalho para um evento, submete um artigo para uma revista ou submete um projeto para um órgão de avaliação e financiamento, e a gente acaba recebendo nãos. Porém, se o parecerista for generoso com a gente, nos ajuda a reverter aquilo que era algo negativo. Aí o que nós fizemos: nós fomos atrás do que havia sido publicado sobre orientação de dissertações e teses. E aí nos damos conta que havia muito pouca coisa registrada e socializada sobre o assunto. De qualquer maneira, nos deu o motivo para organizar e publicar a coletânea A Bússola do Escrever. Desafios e Estratégias na Orientação e Escrita de Dissertações e Teses (editora Cortez), que trata da temática da orientação de dissertações e teses, que incluiu artigos "perdidos", como o do Cláudio Moura Castro, publicado originalmente em 1974 e artigos encomendados a pesquisadores que se dispuseram a escrever sobre suas experiências e reflexões relacionadas ao assunto. A partir daí, minha trajetória de pesquisa foi toda pautada por essa questão da orientação de dissertações e teses, a coordenação, CAPES e financiamento. E isto acabou ocorrendo por uma questão muito simples. Em 2000, 2001, por aí, nós submetemos um projeto ao Edital Universal do CNPq com o mesmo título daquele que encaminhamos para aquele evento, com a diferença que colocamos na frente a expressão "política educacional", ficando então assim: "Política educacional. Orientação e escrita de dissertações e teses em questão: produção científica \& estratégias de orientadores e coordenadores de programas de pósgraduação em educação". Daí em diante terminamos esse projeto e em 2005 entrei no CNPq com um projeto que mantinha praticamente a mesma denominação. Porém, a entrada foi individual, candidatando-me a pesquisador produtividade (PQ). E a partir de 2005 até hoje eu venho me mantendo como pesquisador do CNPq. Comecei como pesquisador PQ2 e hoje estou na condição pesquisador 1B, sempre mantendo essa temática da orientação de dissertações e teses. Por quê? Porque na medida em que a gente ia fazendo entrevistas - temos 72 entrevistas feitas com 
orientadores experientes de programas bem avaliados -, a temática foi se evidenciando cada vez mais interessante.

MFV: Em que sentido?

LB: Às vezes a questão da orientação e escrita é decisiva na conclusão de um mestrado, de um doutorado. $\mathrm{E}$, contraditoriamente, há pouca coisa registrada e publicada sobre o assunto, embora recentemente esse quadro venha mudando. É uma temática que, como diria Maria Teresa Haguette, no artigo que está no Bússola do Escrever, fica nos "bastidores da produção de conhecimento" na universidade. O que nós fizemos com nossas pesquisas e que eu continuo fazendo até hoje, foi trazer para a frente, trazer para o palco o que estava nos bastidores. E na medida em que fizemos isso, uma espécie de link, de um hipertexto abre-se e uma nova temática da pós-graduação passou a frequentar as páginas de livros, de artigos de periódicos, relacionada à especificidade da orientação. Por exemplo, eu diria que um dos primeiros livros que surgiu no Brasil sobre isso, depois do Bússola do Escrever, que traz inclusive no título essa questão da orientação de dissertações e teses, foi o da Sueli Mazzilli, supervisionada no estágio pós-doutoral pela professora Maria Isabel da Cunha na Unisinos, cujo título é Orientação de dissertações e teses: em que consiste? (editora Junqeira e Marins).

MFV: Mas isso já é depois do teu projeto de pesquisa.

LB: Esse é um livro que surge em 2009. Ele é publicado em 2009, e Ana Maria Netto Machado e eu somos muito citados, direta ou indiretamente, porque já havíamos publicado o Bússola do Escrever em 2002. Mas daí, Moacir, só para ir fechando e caminharmos para as demais questões, em 2014 eu me aposentei depois de 32 de magistério. Porém, continuei como professor Voluntário, no PPGE/UFSC, orientando, oferecendo um Seminário por ano, coordenando um grupo de Pesquisa ("Trabalho e Conhecimento na Educação Superior" - TRACES) e continuando minha pesquisa pelo CNPq. E aí o que aconteceu em 2014? Como eu me aposentei e terminava um dos projetos do CNPq, resolvi resgatar aquela discussão de 1999 e transformar em projeto de pesquisa para o CNPq. Apresentei como projeto, "Orientação de dissertações e teses: do intuitivo-individual para o coletivo-grupal. Em direção a uma pedagogia da orientação". Seguindo neste raciocínio, vou entrar na pergunta que você me fez: quais são as questões mais importantes dessa temática? O que a questão da orientação e escrita de dissertações e teses, no contexto da práxis, me diz, o que ela suscita? Eu quero dizer que nas falas/palestras para as quais eu sou convidado para tratar deste tema, nunca falta assunto, porque, seja do ponto de vista antropológico, do ritual de passagem, a defesa como culminância da orientação, seja do ponto de vista psicológico, que numa relação orientador-orientando mobiliza questões de transferência, contratransferência, sublimação enfim, questões que o Freud teria muito o que falar, é um tempo assim riquíssimo do ponto de vista pedagógico. E a gente é alguém que caminha com, alguém que ensina e aprende. É uma relação que pode ser fluida, de amizade, de manutenção para o resto da vida, como pode ser uma relação muitas vezes atravessada por conflitos que precisam ser trabalhados e precisam ser geridos para que o processo e o resultado não sejam afetados por esse problema, vamos dizer assim, por esse ruído na relação. E aí, sinteticamente, eu te diria o seguinte: que eu não tenho dúvidas de que, seja pelo fato de eu ter encaminhado o projeto com o título que eu 
acabei de dizer ("Orientação de dissertações e teses: do intuitivo-individual para o coletivo grupal"), ou seja, da relação do orientador-orientando para o coletivo-grupal, em direção à rede, eu não tenho dúvidas de que a orientação no grupo, com o grupo, é aprendizagem, é a questão pedagógica mais importante nessa minha trajetória de leituras e de pesquisa. Isto é, se você tem um grupo de pesquisa, esse grupo é composto por componentes heterogêneos que vão da iniciação científica ao pósdoutorado. Você acaba tendo um colega de pesquisa que está trabalhando com você. A questão da orientação se dilui naquela problemática que ela era quando se resumia na relação orientadororientando. Ela se dilui no coletivo, porque o aluno de iniciação científica tem chance, nas reuniões, de fazer intervenções, eu costumo dizer, de dar pitacos sobre o projeto do doutorando, sobre a pré-defesa ou a pré-qualificação, atividades que a gente sempre faz no grupo. Portanto, aquela questão do ritual de passagem a que eu me referia que o aluno ficava nervoso na defesa, porque era a primeira vez que ele estava defendendo, com grupo de pesquisa até isso se relativiza, porque ele faz um exercício com os colegas, com outros professores que estão na condição de quem está fazendo uma leitura crítica, mas na perspectiva de ajudá-lo, de fazê-lo catapultar-se, de fazer da defesa um passo para ele chegar a titular-se. Então, se tem algo que eu aprendi muito nesse processo, seja de pesquisa, seja de leituras de grupo de pesquisa, é que aquelas discussões iniciadas, principalmente por um grupo de professores da Universidade de Nottingham, na Inglaterra, sobre a orientação como uma "didática, uma pedagogia" que pode ser ensinada e apreendida (Cf. The Routledge Coctoral Supervisor's Companion. Supporting effective research in Educacion and the Social Sciênce, Ed. By Melanie Walker and Pat Thomson, Routledge - Taylor \& Francis Group), é de que a orientação é, sim, uma temática que merece, precisa ser pesquisada em função de tudo o que nesse processo está envolvido. Eu diria que, se antes pensava que a orientação não poderia ser ensinada e aprendida, hoje penso que é possível aprender/ensinar no processo de ser orientado e de orientar, porém deve-se estar vigilantes para não sucumbir a engessamentos, a começar a escrever e "consumir" manuais de orientação como se isto não fosse algo a ser aprendido no processo. Ocorre que cada orientação é um processo, cada relação orientador-orientando é única, e não tem uma aprendizagem que você possa dizer assim, que eu vou transferi-la diretamente de um processo de orientação com um orientando para outro. Não há essa possibilidade, os processos são únicos. Mas o exercício do processo de orientação em grupo tem sido a maior aprendizagem desses longos anos de pesquisa na pós-graduação.

MFV: Outra questão que tu trouxeste, que também recentemente foi teu tema de pesquisa, e que gerou várias produções, é o produtivismo acadêmico. Esta é atualmente uma situação que a gente enfrenta como professor de pós-graduação, e os alunos também. Desde muito jovens já enfrentam isso, inclusive já na iniciação científica. Essa preocupação, que até algum tempo atrás não existia, hoje já é sofrida por estudantes de 17, 18 anos. E aí temos todo o estresse e problemas de saúde que isso também causa. Todos no ambiente acadêmico falam do produtivismo, mas parece que pouco se explica esse fenômeno, o que ele significa e como podemos enfrentá-lo. Em termos de tendência, tu achas que esse fenômeno vai continuar ou existe alguma chance de mudança?

LB: Boa pergunta. Para começar, eu não sou contra a produção. O problema é quando essa produção passa de uma atividade inerente ao nosso ser professor, ser pesquisador, que é construir o 
conhecimento e veiculá-lo, para, eu diria assim, uma ideologia. Isto é, se transforma num produtivismo, essa palavra que, desafortunadamente, se transfere do mundo da produção para o mundo acadêmico. Eu diria, para começar, que muito da reação que há em relação à produção, e veja bem, eu não falei em produtivismo e sim em produção, e a necessidade de veiculação desse conhecimento, eu diria que, em nome do produtivismo, muita gente faz dele um álibi para não produzir nada. É como se ser produtivista fosse até nome feio. Na verdade, quando predomina esse componente econômico, ou da economia acadêmica, se torna verdadeira e justificada essa questão de uma reação a um produtivismo que é simplesmente uma resposta a uma indução que traz problemas. Porque se é uma indução muito forte, as pessoas buscam estratégias de superação para atender os requisitos. Mas vamos lá, antes de chegar a isso, o Antônio Zuin, da UFSCar e a Obdália Ferraz, da Universidade Estadual da Bahia e eu, acabamos de publicar um livro que se chama, Publique, Apareça ou Pereça: produtivismo acadêmico, "pesquisa administrada" e plágio nos tempos da cultura digital (Editora da UFBA). E do que trata o livro? Tentamos fazer uma reflexão sobre a necessidade e a obrigação que temos de ter um tempo disponível para escrever, para produzir. Particularmente quando um pós-graduando conta com bolsa, ou um professor com financiamento para pesquisar, é uma obrigação que se nos coloca de veicular esse conhecimento, de passar para outras pessoas. Mas, no livro, nós começamos mostrando como a expressão publish or perish aparece e quando/como foi utilizada. Ela se tornou comum na economia na década de 1940 e adentra o mundo acadêmico na década de 1960, nos campi norte-americanos. Nesse processo vamos conhecer todas as vantagens do incremento na produção, na socialização do conhecimento e todas as mazelas que se seguem àquilo que é resultante de uma indução. Tanto que quando se brinca hoje, por exemplo, dizendo que "artigos passados não movem o Lattes", isso é uma brincadeira, uma gozação, um chiste sobre o quanto aquilo que nós produzimos, lemos, escrevemos, tem uma espécie de vida útil curta para a avaliação. $E$ isso faz com que se entre, muitas vezes até histericamente, nessa discussão sobre o produtivismo. Eu reforço que esta reação, em muitos aspectos, é um álibi, porque, se nós temos tempo disponível para dedicar a isso, seja mestrandos, seja doutorandos, ou professores, nós temos a obrigação da contrapartida que é a socialização dos nossos achados, das nossas descobertas. É claro que a forma como estamos sendo induzidos cria o problema da tensão, até das neuroses e bloqueamentos, da síndrome da tela em branco, principalmente para jovens mestres e doutores que estão chegando ao mestrado e ao doutorado cada vez mais novos, com menos experiência do que quando a pós-graduação foi criada. Então eu diria que nós precisamos tratar dessa questão com a seriedade que ela merece, fazer a crítica que ela enseja. Como fazemos nesse livro, mostrando como, da economia se entra na academia, com um viés economicista, o que se torna um grande problema. Mas que há meios, há estratégias de trabalhar, de fazer um qualificado enfrentamento a essa questão, só que nós não tínhamos essa prática. Por exemplo, nós não tínhamos a prática da coautoria e nem havia muita clareza sobre a importância do orientador escrever com o orientando, a experiência da coautoria. Não tínhamos essa prática. A pós-graduação é muito jovem no país. Nós não tínhamos sequer precedentes sobre esse aspecto. Mas eu diria, assim, que procuro ir escrevendo com meus orientandos de Iniciação Científica a partir de desafios menores, embora não menos importantes. O menor aqui não é exatamente porque ele é menos importante, mas porque é um desafio menor em termos de implicações. Nesta direção, se você está dando uma disciplina, com 
diversos livros nas referências, porque não, ao invés de pedir um trabalho de final do curso, você não pede para o teu grupo de alunos, atribuindo a cada um deles uma incumbência de fazer uma resenha de cada um dos livros que você indica, porque, nas revistas sobram artigos para publicar, mas faltam resenhas. Por exemplo, do livro em coautoria com o Valdemar Sguissardi: Da Univeridade à Commoditycidade (editora Mercado de Letras), publicado no final de 2017, já conta com resenhas em revistas importantes. E isso é uma estratégia de escrever juntos, o orientador e o orientando, de os alunos escreverem coletivamente. Aí vem um grande problema que é, muitas vezes ter que publicar em revistas B3, B4, B5, que não valem ou não são levadas em conta na avaliação do docente, mas valem muito para o discente. Porque se você olhar na avaliação da CAPES, 35\% da avaliação envolve o corpo discente. Então, essa é uma vantagem. A segunda vantagem é que a gente ajuda como orientadores, como pesquisadores, a qualificar mais periódicos, que de outra forma ficariam para trás ou não melhorariam sua avaliação Qualis. Em síntese, te diria que a questão da produção, da publicação, do produtivismo, a gente resolve quando tem um grupo de pesquisa, e quando você tem pesquisas e nessas pesquisas você não é uma abelha que fica pulando, passando de uma flor para outra para colher o néctar. $O$ passo adiante é dedicar-se a uma temática, verticalizar nessa temática, permanecendo fiel a ela, de tal forma que a produção seja uma decorrência e não um problema. Nesta perspectiva você não precisa se preocupar se está faltando um artigo ou tenho que produzir esse até outubro para completar o número exigido pela CAPES. Não pode ser desta forma, como se fosse atender a uma demanda. Se há pesquisa, socialização, o número e a qualidade das publicações é decorrência de um processo, pois assim não precisa ficar se preocupando que as revistas boas não publicam em até dois anos após a submissão. Se for mantido o fluxo de produção-socialização, o número de artigos deixará de ser um problema. Então a estratégia é manter-se fiel a uma temática, manter-se vinculado a um grupo de pesquisa, manter-se desafiando os orientandos a fim de que, daquele trabalho, que é um trabalho que é coletivo, uma parte que seja recortada se transforme em um artigo, principalmente depois da defesa. Portanto, a publicação deve ser uma decorrência do trabalho feito anteriormente. Por fim, nessa questão, eu registro o aspecto negativo, que é o problema da indução, isto é, quanto há uma percepção, uma concepção de que nós estamos sendo obrigados. Isto não deixa de ter um fundo de verdade. Nós somos obrigados a produzir tantos artigos para permanecer credenciados no mestrado e no doutorado. De outra parte, em relação aos discentes, há programas que vinculam a qualificação ou a defesa a um artigo aceito em um periódico. Se isso for engessado, se for captado dessa forma, como uma obrigação, e não como uma resultante de um processo... o plágio pode ser explicado, em parte, pela forte indução advinda dos órgãos de avaliação e financiamento. Mas, voltando, de que forma pode-se superar esta questão de apreender a necessária produção frente ao produtivismo induzido? Com a pesquisa, com o grupo de pesquisa, com a fidelidade a uma temática e com um trabalho muito próximo aos orientandos, sempre tendo como horizonte que aquilo que se pesquisa precisa ser socializado. $\mathrm{O}$ orientador precisa se preocupar com aquilo que é a necessidade de se preencher um determinado número de artigos no quadriênio, mas ao mesmo tempo saber que precisa orientar, acolher, acompanhar o seu orientando naqueles primeiros e titubeantes passos de ingressar nesse fantástico mundo que é o mundo da autoria. 
MFV: Muito obrigado. Tu já vens trazendo na tua fala uma questão que talvez seja a principal que a gente gostaria de perguntar, que é em relação à situação atual da pós-graduação e as tendências que tu vês pela frente. Entre outras coisas, a gente tem o problema dos recursos para a pós-graduação, que têm diminuído ano a ano. Temos uma conjuntura política que, ao que parece, pelo menos a curto prazo, indica que essa tendência deverá continuar. Como tu avalias essa situação e que perspectivas tu vê pela frente?

LB: Bom, Moacir, a primeira questão é que a gente tem presente o momento que estamos vivendo agora e que mimetiza, embora com tons muito mais cinzas, muito mais complicados, o período da eleição do Fernando Collor de Mello. Ao assumir, Collor extingue a Capes. Por dois meses a Capes deixa de existir. O ministro da educação era o José Goldenberg. E o interessante foi que a comunidade cientifica se levantou num movimento muito forte contra a extinção da Capes, com o seguinte argumento: com a Capes é ruim, sem ela é pior. E a Capes foi recriada, mas eu diria que ela veio, na recriação, inoculada com um Cavalo de Troia, isto é, ela veio como fundação, com um orçamento que permitia avaliar e financiar os programas. E toda vez que você acopla o financiamento com a avaliação, um desses pares, a avaliação, sai mais prejudicada. Eu diria que o conceito de avaliação, quando acoplado ao de financiamento, fica bastante complicado, porque você prioriza o ranking, a classificação, os bons resultados para ter o retorno em termos de recursos. Então, essa primeira observação é em relação a tua pergunta. A segunda, é o seguinte: não podemos deixar de reconhecer a importância do sistema Capes de avaliação e financiamento, na gênese e no desenvolvimento daquilo que nós conhecemos hoje, como Sistema Nacional de Pós-Graduação. Tem uma série de vantagens, basta ver nossos países vizinhos e outros países, que, não tendo um sistema de pósgraduação, ficam carentes de coisas que nós dispomos. Mas junto com isso de que nós dispomos, que é uma grande vantagem, não deixam de estar os problemas que são apresentados, discutidos na Anped, no Fórum de Coordenadores, que não caberiam numa entrevista. Por exemplo, comentando o documento recentemente divulgado pela Capes, sobre a "Proposta de Aprimoramento do Modelo de Avaliação da Pós-graduação", observo que em sua terceira página tem uma frase que me chamou muita atenção. É dito que o "atual sistema avaliativo atingiu um ponto de esgotamento e deve ser conceitual e objetivamente repensado e aprimorado". Então, veja, da própria percepção das autoridades há uma compreensão de que o modelo chegou a um ponto que ele precisa ser revisto. $\mathrm{E}$ eu diria que nós, da área de Educação, de Ciências Sociais e Humanas em geral, nesse modelo de avaliação, somos os mais prejudicados, porque o modelo é estatístico, ele é econométrico, ele é de medidas. Temos muitos itens em que somos avaliados e que não podem ser quantificados. Então saúdo esse documento, considerando que é uma boa iniciativa da CAPES. A própria ANPEd, a SBPC e outras sociedades científicas vêm externando suas posições. Porque, do ponto de vista de determinadas ciências, o modelo funciona bem, e funcionou também em alguns aspectos na área de sociais e humanas. Mas na medida em que utilizou a mesma métrica, o mesmo trampolim, a mesma medida, algumas áreas passaram a ser prejudicadas e outras a ter vantagens. $E$ como são recursos que estão em jogo, evidentemente há áreas que não estão interessadas na mudança. Mas nós, da área de sociais e humanas, certamente estamos muito interessados, e o documento aponta para 
questões que do nosso ponto de vista são reiteradamente explicitadas, permeadas por muitas reclamações. Por exemplo, como avaliar inserção social apenas em termos numéricos? Como não se dar conta de que há uma assimetria na distribuição dos Programas de Pós-Graduação pelo país, na medida em que universidades privadas, naquele sentido do interesse por retorno, fazem da PósGraduação um meio de legitimar-se como universidade e, portanto, conquistar autonomia e daí ter outras vantagens. Então, como não se dar conta do problema da medida de inserção social, de relação com a educação básica, da assimetria regional que classificaria como verdadeiros apagões que ainda há no país em termos da cobertura da Pós-Graduação. Porque não havendo ampliação no número de universidades públicas e comunitárias e, de sua parte, as universidades privadas não têm interesse em investir nesses lugares onde não há retorno. Enfim, embora vendo com boas perspectivas o documento, terminei a leitura com uma frustração. A de que a revisão que está sendo proposta é uma revisão para aprimorar os critérios que estão aí, e que já demonstraram para algumas áreas que não são adequados ou que se esgotaram. Então, quando se olha para a proposta em perspectiva, o que perpassa no documento é a perspectiva do aprimoramento daquilo que nós já conhecemos. Fica uma preocupação muito grande sobre os desdobramentos a respeito daquilo que vem pela frente. Por exemplo, para nós é ótimo que se fale em auto-avaliação. A questão é: qual o peso que isso vai ter no instrumento de avaliação, que é homogêneo para áreas e realidades heterogêneas? Temos aí, então, um complicador. E a questão que também me chamou atenção na leitura do documento, que me deixa um gosto amargo, é que não há uma defesa contundente no sentido da necessidade da ampliação de recursos. Dito desta forma, direta, são necessários mais recursos e não há menções sobre ajudar programas que estão em situação mais difícil e que seriam aqueles que teriam mais necessidade. $\mathrm{O}$ que está previsto é que os programas ou vão para o nível de excelência, de internacionalização, ou estão jogados à sua própria sorte. Falando nisto, nós do PPGE/UFSC, estamos passando por uma experiência amarga, agora, de rebaixamento, de passar de nota 5 para 4. Isso veio acompanhado de corte de recursos num momento em que aquilo de que mais se precisa é de incentivo. Se há um PROEX para os programas 6 e 7, deveria haver meios de alavancar quem, por algum motivo, teve seu programa rebaixado. E isto poderia ser providenciado pela própria IES ou pela CAPES, visando colaborar com programas que estão começando, ou aqueles que, por contingências históricas, regionais, estruturais, conjunturais perderam a sua nota, e sofrerem penalizações. Toda vez que essa questão entra em discussão, vem à minha mente a tese da Lara C. Thiengo, minha orientanda que acabou de defender a tese Universidades de classe mundial e o consenso pela excelência: tendências globais e locais. Lembro dos momentos de orientação quando este assunto vinha à tona. Isto é, aquelas universidades ou cursos que vão bem, são premiados, estão liberados para fazer convênios ou conseguir recursos de fontes diversas, ao passo que os programas que tiveram algum tropeço, e que mais necessitam, são penalizados. Com a Lara discutíamos o quanto havia nisso daquele adágio bíblico: "Ao que tem muito, mais lhe será dado, e ele terá em abundância. Mas ao que quase não tem até mesmo o pouco que tem Ihe será tirado" (Mateus, cap. 25, vers. 29).

MFV: Exatamente. 
LB: Penso que isso fecha essa nossa parte da discussão sobre a Pós-Graduação. Quer dizer, na medida em esta continuar sendo homogênea para áreas e realidades heterogêneas, haverá privilegiados e prejudicados. Algo semelhante ocorre intra programas e entre áreas. Hoje, por exemplo, está em alta a discussão sobre a inutilidade das humanidades, das ciências sociais e humanas, uma vez que trazemos poucos retornos imediatos para o mercado. Ocorre que a nossa discussão não se esgota no presente, não é destituída de intencionalidades, portanto, nós não nos encaixamos nos sagrados mandamentos da neutralidade e da objetividade científica. São características de área.

MFV: Nesse contexto, Lucídio, que tu trazes aí, os desafios que enfrentam os programas, pensando em programas relativamente jovens, como o nosso programa aqui da UNISC, temos aí 10 anos de existência, portanto somos um programa relativamente jovem, e que tem uma bela caminhada, que tu estás podendo acompanhar. Já temos o doutorado, agora vamos ter o primeiro Minter também. Mas é um contexto também de muitos desafios, em função dessas questões todas que tu trouxeste. Poderias falar um pouco sobre isso, sobre essa caminhada inicial dos programas mais jovens? Quais os principais desafios que eles têm pela frente?

LB: Bom, Moacir, começo parabenizando o programa de Pós-Graduação em Educação da UNISC pelos seus 10 anos, que parecem, a um olhar externo, poucos. Mas para quem desencadeou o processo, para quem viveu momento a momento, no dia a dia, as angústias, as agruras e as alegrias de construir um programa, como você e teus colegas, deve ser motivo de festejos, sim, porque tudo aconteceu em uma ambiência de muitos problemas, impedimentos, dificuldades. E vocês foram pautando-se por uma persistência, por uma crença na diferença que a Pós-Graduação faria, seja para a área de humanas, seja para a universidade como num todo. Então não posso deixar de cumprimentar e de dizer que me sinto muito distinguido e gratificado de ter acompanhado de perto esse processo e perceber o quanto vocês foram persistentes e o quanto merecem hoje estar na condição de capitanear, seja uma formação no interior da universidade, na sua área de abrangência, e principalmente na abertura de um primeiro Minter, que é uma experiência fantástica de apadrinhar, de dar cobertura a instituições que estão vindo logo atrás e que também estarão dando os passos que vocês deram. Assim como eu, olhando para o nosso programa, olho para trás e vejo que avançamos, tivemos muitas conquistas e passamos por muitas dificuldades, como é da humana natureza e das relações institucionais, principalmente essas que envolvem a necessidade de recursos, de subsídios. Então diria o seguinte, bastaria se perguntar quantas vezes e em quantos momentos vocês tiveram que remar contra a corrente e, inclusive, dentro da própria instituição, internamente, para se legitimar como um grupo. Se dentro da instituição, onde vocês são conhecidos e são respeitados, tiveram que remar contra dificuldades, e ao mesmo tempo vieram tendo os apoios que permitiram a vocês estar hoje comemorando 10 anos, imagina o que significa para o programa que está começando, para um programa que dá os seus primeiros passos num contexto de tanta competição, como é o contexto da Pós-Graduação, frente a uma realidade de financiamento a partir do alcance de alguns indicadores. E para alcançar esses indicadores -, usando uma metáfora - "quando existe um cobertor curto e muitos passando frio", é necessário remar contra a maré, como falei, muitas vezes, inclusive internamente na instituição. E o mais das vezes, no contexto da área, e também inter-áreas, porque toda vez que um 
novo programa aparece e entra no Sistema Nacional de Pós-Graduação, é mais alguém disputando recursos cada vez mais exíguos. Então, esse é um lado, que eu diria assim, perverso, que deve permitir, suscitar a vocês, reflexões sobre como foram se mantendo fiéis a um ideário, como vieram acreditando no potencial de vocês e como hoje estão legitimados na condição de formadores de formadores, como estão legitimados como um grupo de professores que constitui um programa, que titula alunos, que faz assessorias, que dá suporte para prefeituras, para movimentos sociais, que faz pesquisa sobre problemas que atingem a região e dão conta de tantas frentes. Enfim, que contribui com aquilo que é das missões da universidade, aquela que mais visivelmente se relaciona com a comunidade, que é a pesquisa, com possibilidade da extensão dos resultados e a extensão resultante dessas descobertas, dessas pesquisas, dessa inserção, dessa imersão numa realidade. Diria que, na curta história da pós-graduação brasileira - está no documento a que fiz referência: a primeira defesa ocorreu em 1963 - e nesse contexto já contamos com mais de 6.500 programas. Então se pensarmos: o que é o PPGEdu da UNISC entre os 6.500 programas? E, no entanto, é um programa que já fez história, é autônomo, tem uma capilaridade, tem uma presença muito qualificada na região, fazendo com que fosse extinto um apagão (educacional) e, em seu lugar ascendendo uma luz, a qual se torna um guia, uma esperança, uma possibilidade para tantas pessoas, seja daqueles alunos imediata e diretamente ligados a vocês, quanto os do Minter daqui a pouco, quanto outros que virão a acessar esse Programa. Frente a isto diria que, se não fosse o idealismo, não fosse a persistência e um corpo docente aguerrido, no individual e no coletivo, não teriam chegado a essas conquistas e se legitimado na instituição, na região e, em termos mais amplos, no contexto do próprio Sistema Nacional de pósgraduação. E é bom recordar que 10 anos, para quem vivenciou a experiência, é uma história intensa, longa. Para quem olha de fora, é uma história curta, como é breve a história da pós-graduação brasileira. E, no entanto, se fez tanto em pouco tempo, que vocês são merecedores de cumprimentos porque não é nada fácil ingressar no sistema e manter-se nele num período com tantas carências, com tantas dificuldades. E isso que está acontecendo com vocês, se nós estivéssemos num ambiente de solidariedade, seria muito mais fácil de superar dificuldades, de se juntar, de somar forças, por exemplo, com a UCS (Universidade de Caxias do Sul), com outras universidades próximas, que vivem realidades muito semelhantes, mas que dada a competição por recursos acaba que cada uma forma núcleos, vai nucleando em torno de si, prevalecendo a competição, quando a tônica deveria ser a solidariedade. Por fim, Moacir, gostaria de fazer um registro a respeito da importância de um Programa, de uma instituição ter uma revista como a Reflexão e Ação. Conheço este periódico há um bom tempo, tendo tido a oportunidade de contribuir algumas vezes com a submissão de artigos. A proposição de um número especial no transcurso dos 10 anos do PPGEdu da Unisc é muito importante. Permite visualizar o quanto a revista contribuiu para a Pós-graduação e esta para a Revista, bem como abre perspectivas. Abrem-se, por exemplo, possibilidades de dossiês, de convites. Vocês alcançaram um patamar de igualdade com aquilo que as instituições têm entre seus pontos de destaque: um periódico para veicular suas produções e atrair a produção de outros quadrantes. Então, ter uma revista é um diferencial para o Programa, porque a revista se torna -, apesar de ter que driblar o problema da endogenia -, uma linha de frente, uma ponta de lança do Programa e, por extensão, da própria instituição, para a socialização daquilo que são os avanços na produção do conhecimento pelo coletivo 
do PPGEdu e dos programas de pós-graduação em geral. Também em relação a isto vocês estão de parabéns, seja pelos 10 anos do PPGEdu, seja por terem tido, em algum momento da história da Unisc, criado uma revista e, apesar das dificuldades, vieram mantendo-a, e hoje é a revista com o prestígio que ela tem. Prestígio que, em uma espécie de círculo virtuoso, passa para o Programa e que - Programa pode reverter em garantias de continuidade e maior qualificação da revista, retroalimentando-se mutuamente, com benefícios para o programa, para a universidade e, em geral, para o entorno e à comunidade científica.

MFV: Lucídio, agradecemos pela oportunidade de realizar essa entrevista. Em tua fala transparece otimismo e a positividade em relação à pós-graduação, mesmo em tempos difíceis que vivemos. Pensamos que essa positividade é parte importante de nossa atuação como professores e pesquisadores. Uma compreensão emancipatória das práticas e fenômenos educacionais deve pautar nossas ações e relações sociais na universidade e na comunidade. Muito obrigado!

\section{Como citar este documumento:}

VIEGAS, Moacir Fernando; BIANCHETTI, Lucídio. Da pós-graduação as escritas sobre orientações de dissertações e teses: uma entrevista com Lucídio Bianchetti. Reflexão e Ação, Santa Cruz do Sul, v. 26, n. 3, nov. 2018. ISSN 1982-9949. Disponível em: <https://online.unisc.br/seer/index.php/reflex/article/view/12856>. Acesso em: 22 nov. 2018. doi:https://doi.org/10.17058/rea.v26i3.12856. 